\title{
EL CALENDARIO SAGRADO: EL PROBLEMA DEL TIEMPO \\ EN LA SOCIOLOGIA DURKHEIMIANA (II) *
}

\section{Ramón Ramos Torre}

RESUMEN. La teoría durkheimiana del tiempo forma parte de una ambiciosa teoría general de las categorías que pretende superar científico-positivamente las aporías tradicionales de la epistemología filosófica. Analizadas las insuficiencias de la reducción social de las categorías y, en particular, del tiempo, en este trabajo se presentan las líneas generales de una teoría del tiempo pos-durkheimiana.

\section{La teoria sociológica del conocimiento y del tiempo}

Es consustancial al sistema teórico de Durkheim no diferenciar entre una sociología y una teoría sociológica del tiempo ${ }^{~}$. La razón radica en un argumento circular fuertemente arraigado en su definición del territorio y método de la sociología. En síntesis, el argumento es el siguiente: para que el tiempo sea susceptible de una aproximación sociológica ha de ser un hecho social, pero si es un hecho social sólo es susceptible de una aproximación sociológica. la REIS.

* Este artículo es continuación del publicado con el mismo título en el núm. 46 de

' Esta confusión es análoga a la que Durkheim comete entre sociología del conocimiento y teoría sociológica del conocimiento, que ha destacado Namer (1977). 
De ahí que lo uno se identifique con lo otro y la sociología se convierta en una teoría general, necesaria y suficiente, del tiempo.

En esto consiste el equívoco de los análisis durkheimianos sobre el tiempo: abordan un tiempo, el tiempo social, pero pretenden agotar y resolver definitivamente el problema general del tiempo. La reacción más generalizada de los estudiosos de Durkheim ha consistido en intentar romper el equívoco, en delimitar los aspectos estrictamente sociológicos de los aspectos llamados «filosóficos», centrando la atención en aquéllos y prescindiendo de estos últimos como puro extravío filosófico propio de una sociología todavía inmadura e insegura ante el problema de la demarcación de los dicursos ${ }^{2}$. Habría así un Durkheim atendible (el sociólogo) y un Durkheim desdeñable o prescindible (el filósofo). El resultado final consistiría en la fijación de una sociología durkheimiana del tiempo desarraigada de toda veleidad teórica general, de toda ambición filosófica. No niego la legitimidad de esta estrategia diseccionadora, aunque me parece que consigue sus objetivos sometiéndose a la servidumbre de toda sentencia salomónica, pues cumple su estricta justicia al precio del sacrificio irremediable de la criatura. $Y$, en efecto, si se separan esos dos aspectos que Durkheim unía, si se atiende sólo a uno de ellos y se desprecia el otro, se hace muy difícil captar en su singularidad lo que Durkheim y su escuela proponían, lo específico de su aproximación al problema del tiempo. Esto es así no sólo porque se acabe perdiendo de vista el marco general en el que se inscribía, sino también porque, al hilo de lo que parecen sus excesos filosóficos, se acumulan intuiciones interesantes o errores instructivos que es preciso analizar en profundidad y reorientar en direcciones más fructíferas.

Son éstas las razones por las que en este artículo se va a analizar la teoría general del tiempo que Durkheim esbozó fundamentalmente en las páginas de Les Formes Elémentaires de la Vie Réligieuse. En la primera sección analizaré la teoría general del conocimiento en la que esa teoría se integra; en la segunda, procederé a realizar una crítica sistemática de sus limitaciones y contradicciones; en la tercera, analizaré el intento durkheimiano de una reducción social del tiempo; en la cuarta y última, esbozaré las líneas generales de una teoría del tiempo que, siguiendo lo acertado de la intuición durkheimiana, no quede prisionera de sus errores.

1. Las páginas introductorias de Les Formes... proponen, con una notable economía de argumentos, dos tesis importantes para el caso que nos

2 Así lo decretaron Sorokin y Merton en su conocido e influyente artículo sobre el tíempo social: «Es preciso declarar desde el principio que no nos interesamos en la controversia sobre la derivación empírica o a priori de la categoría de tiempo. Gran parte del análisis realizado por Durkheim sobre el tiempo está viciado por su esfuerzo en ubicarlo en este contexto, lo que le lleva a sostener argumentos no susceptibles de tratamiento científico» (P. Sorokin y R. K. Merton, 1937: 45). La posterior sociología del tiempo no ha hecho sino seguir este camino. 
ocupa: la primera dice que el tiempo es una más de las categorías del conocimiento; la segunda, que las categorías son representaciones colectivas. En el primer caso, se define el marco o territorio genérico en el que el problema del tiempo ha de ser abordado; en el segundo, se define la hipótesis central de una sociología del conocimiento que, como se verá, quiere sustituir a la vieja epistemología filosófica.

Siguiendo a Renouvier, pero sobre todo a su malogrado amigo Hamelin, Durkheim desoye la distinción kantiana entre las formas a priori de la sensibilidad (espacio y tiempo) y las formas a priori del entendimiento o categorías propiamente dichas. A su entender, nada sustancial separa esos dos casos, por lo que es legítimo utilizar un término común para designarlos (Durkheim, 1912: 13). Resulta así que tiempo y espacio quedan asimilados a la causalidad, la cantidad, la sustancia, el género y la personalidad, que constituyen, al menos provisionalmente, el sistema de las categorías ${ }^{3}$.

Pero ¿qué entiende Durkheim por categorías? Al menos tres cosas distintas, de cuyas diferencias no es consciente. En efecto, en un principio parece seguir la vía kantiana de la filosofía trascendental: las categorías son las formas que hacen posible el conocimiento e informan la sensibilidad o el entendimiento del sujeto conocedor ${ }^{4}$. A renglón seguido, sin embargo, las categorías aparecen, en una versión más aristotélico-escolástica, como suprema rerum genera, es decir, como las determinaciones últimas y cruciales de las cosas $^{5}$. El concepto se hace todavía más complejo y confuso al tender Durkheim - tanto en Les Formes... como sobre todo en el artículo sobre las clasificaciones primitivas - a identificar sin más las categorías con las categorizaciones o clasificaciones, es decir, al asimilar lo que es una competencia subjetiva o una determinación objetiva con sus materializaciones o concreciones.

El resultado es un concepto gaseoso, de perfues cambiantes según contextos, lo que incide sobre el análisis a que Durkheim lo somete. Gran parte de sus insuficiencias provienen justamente de los saltos semánticos que se operan en sus argumentos, en los que la perspectiva trascendental se convierte en ontológica y cualquiera de ambas se identifica sin más con la clasificatoria o de las categorizaciones.

${ }^{3}$ Esta es la lista de categorías que aparece en las páginas de Les Formes... (Durkheim, 1912: 13) y que se presenta como abierta, pues se cierra con un etcétera. Cada una recibe un análisis, más o menos somero, en las páginas posteriores de la obra.

+ $\mathrm{Y}$ así se definen las categorías como «cierto número de nociones esenciales que dominan nuestra entera vida intelectual», «sólidos marcos que delimitan el pensamiento", «el esqueleto del pensamiento» cuya ausencia nos impediría pensar (Durkheim, 1912: 12-13). En páginas posteriores se insiste en la idea y se dice que «la razón no es otra cosa que el conjunto de las categorías fundamentales», o se habla de la lógica como el espacio «que las categorías tienen por función reglamentar y organizar» (Durkheim, ibid.: 19).

${ }_{5}^{5}$ En estc sentido, las categorías son presentadas como las nociones que «corresponden a las propiedades más universales de las cosas» (Durkheim, 1912: 13) o como «los conceptos más generales que existen» (Durkheim, ibid.: 19). 
El problema general de las categorías es abordado por Durkheim en dos frentes que, aunque aparezcan mezclados en los textos, conviene diferenciar. Al primero de ellos cabe designarlo frente epistemológico, pues en él, en polémica con los filósofos, pretende Durkheim alcanzar una solución definitiva al problema de la fundamentación del conocimiento. Un segundo frente es el que denomino bistórico, en el que se debate la relación entre los dos sistemas de conocimiento que se han sucedido en la historia humana, el sistema mítico-religioso y el sistema científico. En ambos frentes se aborda el problema general de las categorías, pero para resolver interrogantes distintos. Más tarde se verá que las respuestas que se dan, aparentemente coherentes, resultan, tras un análisis más detenido, claramente enfrentadas.

El frente epistemológico lleva a una confrontación con la tradición de la filosofía de orientación epistemológica. Durkheim acusa a los filósofos de incapacidad para resolver el problema de la fundamentación del conocimiento por haberse empantanado en un dilema esterilizante a la hora de abordar el problema de las categorías. Los polos del dilema los definen las dos tradiciones filosóficas dominantes: la tradición empirista quiere explicar las categorías, pero no lo consigue al no poder derivar de la experiencia sensible su universalidad y necesidad; la tradición racionalista o apriorista reconoce, por el contrario, su carácter universal y necesario, pero se limita a postularlo sin darle ninguna explicación (Durkheim, 1912: 18-21). La alternativa que Durkheim propone consiste en convertir en conjunción esta disyunción, operar una síntesis de los polos del dilema. Las categorías han de fundamentarse a priori y a posteriori a la vez. Y Durkheim cree conseguirlo concibiéndolas como representaciones colectivas en las que se expresa el carácter empírico y a priori del objeto que representan, es decir, la sociedad ${ }^{6}$.

Con esta propuesta tan simple y rápida cree Durkheim superados siglos de estériles polémicas epistemológicas y consumado el feliz matrimonio entre el empirismo y el racionalismo. A partir de esta tesis general, la labor de Durkheim se ciñe a la demostración de cómo las categorías son representaciones colectivas, para lo cual se apoya en una amplia evidencia etnográfica.

Aunque la demostración no es muy sistemática, su núcleo central consiste en probar que las notas características de las categorías coinciden con las determinaciones definitorias de las representaciones colectivas. Dada la com-

- El argumento de Durkheim es el siguiente: si se admite el origen social de las categorías, si se conciben como representaciones colectivas, entonces podemos explicarlas -es decir, derivarlas- empíricamente, como resultado de las determinaciones propias de la sociedad, que, subraya Durkheim, «es un reino natural que no difiere del resto de la naturaleza más que por su mayor complejidad» (Durkheim, 1912: 25); pero, a la vez, podemos reconocerles su irreductible carácter a priori, ya que, siendo sociales, son previas a, y no se derivan de, la experiencia individual (Durkheim, ibid.: 22-23). Toda la argumentación se apoya explícitamente en la hipótesis de la dualidad de la naturaleza humana Durkheim, ibid.: 23. 
plejidad de este último concepto ${ }^{7}$, la demostración se desarrolla, al menos, de cuatro maneras diferentes: a) formal, mostrando cómo las categorías adoptan la forma de las representaciones colectivas, es decir, son socialmente obligatorias o necesarias ${ }^{8}$; b) funcional, mostrando que son funcionales con el mantenimiento de las estructuras sociales ${ }^{9}$; c) expresiva, mostrando que son la expresión o reflejo de determinaciones morfológicas profundas de los grupos sociales ${ }^{10} ;$ d) genética, mostrando que son el producto de síntesis sociales emergentes que no se pueden derivar de los individuos ${ }^{11}$.

Los resultados de esta batería de demostraciones, aunque brillantes y sugestivos, resultan más bien problemáticos. Las razones de ello son empíricas y teórico-conceptuales, a la vez. En efecto, la crítica posterior ha mostrado la debilidad de la evidencia etnográfica en la que Durkheim se apoya ${ }^{12}$, pero, además, resulta que la entera demostración se edifica sobre una acrítica identificación de la competencia categorial (o categorías propiamente dichas) y la ejecución categorial (o categorizaciones). Durkheim quiere probar el carácter social de las categorías, pero se limita a mostrar el carácter social de las categorizaciones o clasificaciones primitivas. A partir de sus «demostraciones» se puede aceptar que esas clasificaciones son formal, funcional, expresiva y genéticamente representaciones colectivas, pero sin prejuzgar o decidir si las categorías también lo son.

Sólo hay un argumento que supera estos límites y afronta directamente la tarea de reducir socialmente las categorías; se trata de esa propuesta teó-

${ }^{7}$ En S. Lukes (1973a: 6-8) se puede leer un buen análisis sobre la complejidad y ambigüedad del concepto de representación colectiva.

${ }^{8}$ «Es la misma autoridad de la sociedad la que se comunica a ciertas maneras de pensar que son como las condiciones indispensables de toda acción común. La necesidad con la que las categorías se nos imponen no es, pues, efecto de simples hábitos (...) tampoco resulta de una necesidad física o metafísica (...) sino un tipo particular de necesidad mo. ral que es a la vida intelectual lo que la obligación moral a la voluntad» (Durkheim, 1912: 24-25).

9 «Si los hombres $(\ldots)$ no tuvieran una concepción homogénea del tiempo, el espacio, la causalidad, el número, etc., se haría imposible cualquier acuerdo (...) y, en consecuencia, cualquier vida en común. La sociedad no puede abandonar las categorías al libre arbitrio particular sin hacer dejación de sí misma. Para existir no sólo precisa un conformismo moral suficiente; hay un mínimo de conformismo lógico del que no puede prescindir» (Durkheim, 1912: 23-24).

${ }^{10}$ «Si las categorías son representaciones esencialmente colectivas es porque traducen ante todo estados de la colectividad: dependen de la manera en que se constituye y organiza, de su morfología, de sus instituciones religiosas, morales, económicas, etc.» (Durkheim, 1912: 22). En el artículo sobre las clasificaciones primitivas se sigue de manera sistemática esta hipótesis que Durkheim llama «sociocéntrica» y que pretende que las primitivas clasificaciones humanas tienen por origen y modelo las clasificaciones sociales (Durkheim y Mauss, 1903: 459).

${ }_{11}$ "Las representaciones colectivas son el producto de una inmensa cooperación que se extiende no sólo en el espacio, sino también en el tiempo; resultan de la asociación, mezcla y combinación de ideas y sentimientos de espíritus particulares; largas series de combinaciones han acumulado en ellas su experiencia y saber» (Durkheim, 1912: 22-23).

${ }_{12}$ En Lukes (1973 a: 445-449) se puede encontrar un buen resumen de las críticas de los antropólogos a los argumentos durkheimianos, con las referencias bibliográficas fundamentales. 
rica general que hace derivar el sistema de las representaciones colectivas de un a priori afectivo ${ }^{13}$. Si esta derivación es correcta, entonces habría que aceptar que tanto las categorías como las categorizaciones son reductibles a pulsiones emocionales mediadas socialmente.

La hipótesis del a priori afectivo informa dos teorías cruciales en este contexto, la de los medios sociales efervescentes y la del simbolismo colectivo. Ambas ocupan las páginas centrales de Les Formes... (libro II, cap. 6) y definen el núcleo teórico de la obra. Su cometido inmediato es dar razón de la génesis y estructura de la religión totémica de las tribus australianas, pero, más allá de esta temática, tienen una proyección teórica general, ya que enfrentan el problema de la constitución de las representaciones colectivas y, consecuentemente, de la fundamentación de todo orden social ${ }^{14}$. La primera de esas teorías puede ser leída, en concreto, como una especificación sobre la génesis y contenido fundamentales de las representaciones colectivas; la segunda, como una propuesta sobre el modo en que operan los mecanismos psicosociales que hacen posibles las clasificaciones primitivas. Y así, si la primera se refiere más directamente a las categorías - como el núcleo fundamental de las representaciones colectivas-, la segunda se proyecta sobre las categorizaciones.

En lo que aquí interesa, la teoría de los medios sociales efervescentes propone que, cuando las interacciones sociales adquieren un cierto grado de intensidad (medios sociales efervescentes), se producen movimientos colectivos de «entusiasmo», «exaltación» o «efervescencia» ${ }^{15}$. La religión —sos-

13 Ya en la parte final del artículo sobre las clasificaciones primitivas se enfatiza el papel de la afectividad social en la génesis y lógica de las clasificaciones primitivas (Durkheim y Mauss, 1903: 458 y ss.), pero la tesis se desarrolla de forma más sistemática y explícita en Les Formes... Recojo la expresión «a priori afectivo», de G. Namer (1977: 58 y ss.). Como es sabido, ha sido Lévi-Strauss quien ha criticado de forma más radical el recurso durkheimiano a la afectividad y las emociones en su teoría de la religión y el totemismo (Lévi-Strauss, 1971: 106-107).

${ }^{14}$ Lo cual se hace explícito en las conclusiones de la obra: «Para que una sociedad pueda acceder a la conciencia de sí misma y mantener al nivel necesario de intensidad el sentimiento de sí misma, es necesario que se reúna y concentre. Ahora bien, esa concentración determina una exaltación de la vida moral que se traduce en un conjunto de concepciones ideales en las que se representa la nueva vida que acaba de hacerse a la luz (...) Una sociedad no puede ni crearse ni recrearse sin crear, a la vez, el ideal. Esa creación (...) es el acto por el que se produce y reproduce periódicamente» (Durkheim, 1912: 603). Queda así clara la relación general entre concentración, efervescencia colectiva, creación de ideales (representaciones colectivas), constitución y reproducción sociales. Es de este modo como la teoría de los medios sociales efervescentes supera su marco expositivo inmediato ligado al totemismo australiano.

${ }^{15}$ Durkheim usa en este contexto metáforas físicas muy expresivas, como la siguiente: «Una vez rcunidos, de su contacto surge una especie de electricidad que los arrastra rápidamente a un grado extraordinario de exaltación» (Durkheim, 1912: 308), y subraya, a continuación, que esa fuerza emergente transforma interiormentte a los interactuantes y metamorfosea su mundo: "Alcanzado tal estado de exaltación, el hombre no se reconoce a sí mismo. Sintiéndose dominado, arrastrado por una especie de poder exterior que hace que piense y actúe de un modo distinto al cotidiano, es natural que le parezca que no es él mismo. Cree haberse convertido en un ser nuevo (...) Y como todos sus compañeros se 
tiene Durkheim - nace «en esos medios efervescentes y de esa misma efervescencia» (Durkheim, 1912: 313). Como la religión no es sino el paradigma de las representaciones colectivas, la tesis es generalizable a todas ellas. Sostener que nacen de las efervescencias colectivas significa, pues, que son el producto de emociones y afectos sociales. Tal sería también el caso de las categorías que no serían el resultado de una razón activada socialmente, sino la objetivación de sentimientos sociales. Las categorías consiguen así una reducción social radical, al derivarse su entero sistema de un a priori social afectivo: son efervescencias objetivadas.

Algo parecido propone la teoría del simbolismo colectivo para las clasificaciones. La hipótesis general es que «la vida social, en todos sus aspectos y en todos los momentos de su historia, sólo es posible gracias a un vasto simbolismo» (Durkheim, 1912: 331). A la hora de dar cuenta de cómo opera ese simbolismo, Durkheim vuelve a subrayar su determinación afectiva: los hombres escogen los símbolos colectivos al azar de sus pulsiones emocionales. Lo cual significa que el simbolismo colectivo $-\mathrm{y}$ su resultado último, las clasificaciones primitivas-, lejos de ser una forma de pensar las relaciones entre los hombres por su homología con las relaciones entre las cosas (LéviStrauss, 1972: 139, 143), es tan sólo una forma de sentir, no sometida a control racional, las relaciones de los hombres y el mundo que los rodea. No hay, pues, una inicial competencia racional que se ejecute en forma de categorizaciones que clasifiquen y ordenen el mundo, sino el producto del azar de las pulsiones emocionales que se apropian afectivamente del mundo.

Categorías y categorizaciones son así reducidas socioafectivamente; el punto de partida del que todo se deriva es ese a priori afectivo. Es evidente que el precio que se paga por esta reducción social radical de las categorías es muy alto: una sorprendente renuncia al racionalismo por parte de un racionalista militante como Durkheim. Pero es así como se cumple de manera completa el programa alternativo a la tradicional epistemología filosófica. $\mathrm{Y}$ es en cste programa, en su esencial problematicidad, en lo que hay centrar la atención.

2. Dejemos a un lado si las clasificaciones primitivas prueban el carácter social de las categorías o los problemas que plantea el recurso a un a priori socioafectivo; estas dificultades de la teoría del conocimiento de Durkheim son menores en comparación con su dificultad crucial: el carácter aporético de su proyecto de una epistemología sociológica. Que Durkheim quiere construir una epistemología es claro por cómo polemiza con los filósofos: critica sus soluciones, pero no la legitimidad del problema (fundamentación del conocimiento) que abordan; no quiere disolver sociológicamente la epistemología, sino esbozar una epistemología alternativa. También es claro que esa alter-

sienten transfigurados de la misma manera (...) todo ocurre como si se hubiera transportado a un mundo especial, (...) un medio poblado de fuerzas excepcionalmente intensas que lo invaden y metamorfosean" (Durkheim, ibid.: 312 ). 
nativa ha de construirse more sociologico. Lo que hay que plantear, pues, es la relación entre epistemología y sociología y, más específicamente, si es factible el proyecto de una epistemología sociológica. Mi respuesta es que no, y esto me proporciona un punto de partida fructífero para detectar los problemas del entero discurso durkheimiano en este campo.

Desde Descartes, la filosofía ha pretendido convertirse en Tribunal Supremo del conocimiento; en esto ha consistido su giro epistemológico. Para esa epistemología de los filósofos, el conocimiento tiene un problema insoslayable de fundamentación que ha de ser afrontado y resuelto si se quieren asegurar sus pretensiones de necesidad y universalidad. No le basta, pues, que estemos razonablemente seguros - subjetiva o intersubjetivamente- de la verdad de nuestros conocimientos, ni le convence su eficacia pragmática, sino que cree necesario un metódico distanciamiento escéptico y afrontar la pregunta radical sobre sus condiciones de posibilidad; no le basta el saber, sino que pretende un saber sobre el saber. El cometido de la epistemología consistiría justamente en acceder a ese saber último, evidente y constrictivo, lo que pretende conseguir desvelando el fundamento irreductible que garantiza definitiva y atemporalmente la universalidad y necesidad del conocimiento ${ }^{16}$.

¿Qué puede aportar una sociología del conocimiento a una epistemología así concebida? En principio parece que nada, pues todo lo más puede informar sobre cómo se utiliza socialmente el conocimiento, cuáles son sus portadores, pero nada de interés sobre sus fundamentos y la verdad. Es cierto que esta respuesta radical se puede matizar y ha sido matizada, pero sin que tenga por resultado asignar una seria autonomía a la sociología. En efecto, es también posible concebirla como una disciplina auxiliar de la epistemología que aporta información relevante para comprender la génesis del error o incluso la génesis de las hipótesis científicas (contexto de la invención). En el primer caso, la sociología del conocimiento mostraría cómo elementos extraños al conocimiento (p. ej., el interés) contaminan lo cognitivo y ayudaría a explicar cómo se produce el error, incluso cómo el error es normalmente insalvable. En el segundo caso mostraría cómo en el contexto de la invención intervienen elementos extraños a la episteme, pero suponiendo que tales elementos se depurarían racionalmente y acabarían por desaparecer en el contexto de la justificación.

En cualquiera de los casos, la investigación sociológica estaría subordinada a la propiamente epistemológica, pues sólo ésta puede fundamentar el conocimiento. Resulta así que si se acepta que hay una insoslayable problemática epistemológica, es decir, que el conocimiento requiere una previa fundamentación, carece de sentido abogar por una epistemología sociológica. La sociología puede ser una fuente de información para la epistemología, o una disciplina que fija uno de los repertorios de problemas que tiene que solu-

16 Para un análisis sistemático del giro epistemológico de la filosofía posterior a Descartes y una crítica de sus insuficiencias, véase R. Rorty (1983). 
cionar, pero nunca puede ser la fuente de sus soluciones. Por decirlo de forma tajante, se puede ser epistemólogo o sociólogo, incluso epistemólogo y sociólogo, pero nunca socioepistemólogo.

$\mathrm{Y}$ es justamente esto último lo que Durkheim pretende ser. Como el proyecto es lógicamente insostenible ${ }^{17}$, su puesta en marcha está sometida a titubeos, tensiones e incoherencias. En cuanto que sociólogo, Durkheim se ve abocado a demostrar que las categorizaciones/categorías son sociodependientes - de la morfología social y/o del simbolismo efervescente- y, consecuentemente, cambiantes; en cuanto que epistemólogo, que responden a la naturaleza a-histórica del conocimiento y lo conocido y que, por lo tanto, garantizan la verdad. Para conciliar tesis tan contradictorias, Durkheim tiene que recurrir a lo que, en última instancia, es un puro truco verbal que explota oportunistamente esa fiuctuación semántica del término categoría que destaqué al principio: la fluctuación que hace que unas veces las categorías sean condiciones de posibilidad del conocimiento y, otras, determinaciones de las mismas cosas (suprema rerum genera). Y, en efecto, cree poder mediar las tensiones de su proyecto argumentando que las categorías que nos permiten conocer son, por su carácter social, calco de las determinaciones profundas del ser social y que, puesto que éste no es sino una región de la naturaleza, son también calco genérico de la naturaleza misma ${ }^{18}$.

Estas dificultades se agudizan y acaban explotando cuando la sociología de las categorías se desplaza del frente epistemológico o de la fundamentación al que antes he denominado frente histórico. En éste se pretende dar cuenta de las diferencias entre el sistema de conocimiento mítico-religioso y el moderno de la ciencia ${ }^{19}$. Atrapado en las redes de su proyecto, Durkheim acaba

"Y de ahí que la socioepistemología de Durkheim hava conscguido una escasísima au. diencia, to que se ha proyectado sobre su entera sociología del conocimiento. Una crítica radical de la sociología del conocimiento de Durkheim se encuentra en Lukes (1973a: $434-449 ; 1973$ b). Una reivindicación actual de Durkheim aparece en Bloor (1982 a), que parte de una lectura bastante libre del artículo sobre las clasificaciones primitivas y Les Formes... y se apoya en Hesse. El texto de Bloor ha dado lugar a una interesante polémica: Lukes (1982), Bloor (1982 b), Hesse (1982).

is El argumento aparece en la introducción de Les Formes... y se especifica en sus conclusiones. En la introducción se recuerda que fundamentar socialmente el conocimiento no significa optar por el convencionalismo; por el contrario, en buena lógica positivista, se sostiene que «si bien la soctedad constituye una realidad específica, no es un dominio aparte e independiente; forma parte de la naturaleza, constituye su manifestación más clevada. E1 reino social es un reino natural que no difiere de los otros más que por su mayor complejidad. Es por ello imposible que la naturaleza, en lo esencial, difiera de sí misma en ambos casos" (Durkheim, 1912: 25). En las conclusiones se subraya la mayor complejidad de lo social como ventaja cognoscitiva. Se dice, en efecto, que los marcos categoriales «no los ha creado artificialmente la sociedad, sino que los encuentra en sí misma y no hace más que tomar conciencia de cllos. Esos cuadros traducen las maneras de ser que se encuentran en todos los niveles de la realidad pero que no aparecen con plena claridad más que en su cima [la sociedad], porque la extrema complejidad de la vida psíquica que allí se desarrolla necesita de un mayor desarrollo de la conciencia» (Durkheim, ibid.: 634; cursivas mías).

${ }_{19}$ Sin que esto signifique que el pensamiento moderno se pueda identificar in toto con el pensamiento científico. Durkheim fue siempre muy explícito sobre la insuficiencia de la 
recorriendo un itinerario laberíntico en el que los enfoques epistemológico, sociológico y socioepistemológico resultan redimensionados o incluso volatilizados. Sus propuestas fundamentales pueden reducirse a dos: a) que no existe solución de continuidad entre las lógicas mítico-religiosa y científica; $b$ ) que, no obstante, los respectivos sistemas de conocimiento tienen diferente valor de verdad.

La primera propuesta marca la conocida diferencia entre Durkheim y la teoría de la mentalidad primitiva de Lévy-Bruhl ${ }^{20}$. Los sistemas mítico-religiosos no son, subraya Durkheim, a-lógicos o pre-lógicos, sino que están informados esencialmente por esa lógica universal que se encuentra también en la ciencia ${ }^{21}$. Este argumento, además, se presenta como una prueba adicional en favor de la epistemología sociológica, ya que probaría que la vida social, origen y expresión de la religión, es una tuente activa de vida lógica.

La especificación que introduce la segunda propuesta es importante. Durkheim sostiene que, en lo que participa en la verdad, el pensamiento mítico-rcligioso no es autoconsciente (los fieles no saben que lo que adoran es la sociedad) y que al utilizar el aparato lógico-categorial lo hace de forma extremada y mediada por el simbolismo afectivo ${ }^{22}$. Lógicamente, y por contraposición, se supone que la ciencia goza de una posesión autoconsciente de la verdad (la sociología nos permite saber qué adoramos), una lógica que opera equilibradamente y una radical neutralización de lo afectivo. Es decir, el conocimiento científico proporciona mejores conocimientos porque es cons-

ciencia para constituir un sistema de representaciones colectivas completo y suficiente. En las sociedades organizadas, sostenía, al ledo de la ciencia habrá siempre espacio para representaciones colectivas de orientación práctico-ideal que no pueden ni deben ser reducidas a enunciados científicos. El tema se aborda explícitamente en las conclusiones de Les Formes..., al definir las relaciones entre religión y ciencia en las modernas condiciones de vida social (Durkheim, 1912: 609-616).

${ }^{20}$ Las críticas a Lévy-Bruhl aparecen ya en Les Formes... (Durkheim, 1912: 336-342, 626-627) y son retomadas y sistematizadas en la reseña de Les Fonctions Mentales dans les Sociétés Infericures que aparece en el núm. XII de L'Année Sociologique: «Nuestro punto de vista es algo diferente del de Lévy-Bruhl. Este, interesado sobre todo en diferenciar esa mentalidad [primitiva] de la nuestra, ha llegado a presentar a veces sus diferencias en forma de antítesis (...) Nosotros estimamos, por el contrario, que estas dos formas de mentalidad humana, por muy diferentes que sean, lejos de derivarse de fuentes diferentes, han nacido la una de la otra y constituyen dos momentos de la misma evolución» (Durkheim, 1913: 659). La polémica Durkheim/Lévy-Bruhl ha sido analizada por Lévi-Strauss (1972: 388) y Horton (1980)

${ }^{21}$ «No hay un abismo entre la lógica del pensamiento rcligioso y la lógica del pensamiento científico. Uno y otro constan de los mismos clementos, pero desigual y diferentemente desarrollados (...) El pensamiento lógico ha existido desde siempre; no ha habido jamás un período histórico en el que los hombres hayan vivido, de una manera crónica, en la confusión y la contradicción» (Durkheim, 1912: 342, 627).

22 «Lo más característico de la lógica del pensamiento religioso primitivo - dice Durkheim- es su gusto natural por las confusiones incondicionales y los contrastes radicales. Tiende al exceso en ambas direcciones. No conoce de medida ni matices, sino que busca los extremos; emplea, en consecuencia, los mecanismos lógicos con una especie de radicalismo, aunque sin ignorar ninguno» (Durkheim, 1912: 342). 
ciente de lo que sabe y lo sabe racionalmente. En consecuencia, si por la primera propuesta se establece que la verdad mítico-religiosa y la científica no son inconmensurables, por la segunda se especifica que no son sin más asimilables: entre ambas existe una historia de la verdad que, siguiendo el modelo evoiucionista, es presentada como el proceso de su paulatino acrecimiento ${ }^{23}$.

El efecto inesperado de la conjunción de estas dos propuestas es que -con independencia de que Durkheim fuera consciente de ello- convierte la epistemología sociológica en una epistemología antropológica o incluso en una antropología del conocimiento limitada a explicar la génesis de los excesos (errores) primitivos. La otra cara de este vuelco es que se declara la radical incompetencia de la epistemología sociológica, y aun de la sociología del conocimiento, para dar cuenta de la constitución y dinámica del pensamiento científico. Curiosamente, Durkheim acaba negando el proyecto de «sociocentrismo» (Durkheim y Mauss, 1903: 459) que se anunciaba en el artículo sobre las clasificaciones primitivas.

En efecto, proponer, como se dice expresivamente en las conclusiones de Les Formes..., que «el concepto, que originariamente es tenido por verdadero por $\mathrm{el} \mathrm{hecho} \mathrm{de} \mathrm{ser} \mathrm{colectivo,} \mathrm{tiende} \mathrm{a} \mathrm{hacerse} \mathrm{colectivo} \mathrm{a} \mathrm{condición}$ de ser tenido por verdadero" (Durkheim, 1912: 624), es tanto como postular una separación entre sociedad y verdad y sostener que la verdad, que en los sistemas primitivos es constituida socialmente, en las culturas científicas es reconocida socialmente. Consecuentemente, la epistemología sociológica se autolimita a epistemoíogía antropológica, ya que sólo es competente para fundamentar la verdad en el caso de las representaciones colectivas primitivas. $Y$ aun en ese campo queda en realidad limitada a una más modesta antropología del conocimiento centrada en el problema del error, ya que su cometido crucial consiste en mostrar cómo el simbolismo afectivo media sobre las operaciones lógicas y cómo las efervescencias colectivas impiden la autoconsciencia de la verdad.

¿Qué ocurre, por el contrario, con el pensamiento científico? Durkheim se limita a insistir sobre la génesis socioevolutiva de las condiciones que posibilitan la ciencia ${ }^{24}$ o a reconocer que la ciencia presupone una opinión

${ }^{23}$ En esto radica la diferencia que Durkheim subraya entre el enfoque sociológico y el del pragmatismo. También el pragmatismo historiza la verdad, mostrando su carácter cambiante (Durkheim, 1955: 55); su problema radica en identificar historificación y disolución de la verdad. Por el contrario, la sociología acepta que la verdad tiene una historia, pero concibiendo ésta como el proceso de su enriquecimiento: «Si las cosas cambian esto no significa que la verdad cambie al mismo tiempo. La verdad, podría decirse, se enriquece, pero no cambia propiamente; tiene ciertamente agregados, acrecimientos en el curso de su desarrollo histórico, pero una cosa es decir que la verdad crece y otra que varía en su naturaleza misma» (Durkheim, ibid.: 110-111).

${ }^{24}$ Retomando el esquema del paso de la solidaridad mecánica (conciencia común) a la solidaridad orgánica (conciencia social), Durkheim propone en Pragmatisme et Sociologie que la verdad científica surge en aquellas condiciones en las que, por el debilitamiento del control de la conciencia común, se hace posible la búsqueda individual de la verdad: 
pública que la rodea de $\mathrm{fe}^{25}$. Pero tanto la génesis social de las condiciones de posibilidad, como esa opinión pública, son externos al desarrollo de la ciencia como discurso cognoscitivo. Las consideraciones de Durkheim sobre el papel de la opinión en la ciencia no se aproximan en nada a un cuestionamiento de la epistemología clásica, ni desde luego prefiguran la reorientación kuhniana. Se limitan a afirmar que la ciencia cuenta con una opinión externa a ella que es una práctica social o representación colectiva; pero no dicen -ni insinúan- que la ciencia sea también una opinión o práctica social o una representación colectiva.

En consecuencia, Durkheim prescinde de su epistemología sociológica para dar cuenta de la ciencia o, lo que es lo mismo, acepta la epistemología clásica que pretende que la verdad científica es producto de una dinámica exclusivamente teórica, demostrable universalmente por procedimientos metódicos. Es más, dados sus argumentos, poco terreno quedaría a una más modesta sociología del conocimiento científico, ya que tendría que dejar fuera de su territorio el análisis del discurso científico mismo y limitarse al de la opinión pública sobre la ciencia.

Así, pues, el paso del frente epistemológico al histórico hace estallar las tensiones que el proyecto de una epistemología sociológica contenía e intentaba ocultar. El resultado final es que queda limitada a una antropología del conocimiento primitivo que, como no podía ser menos, explicaría por qué nuestros «ancestros» contemporáneos, sin dejar de ser contemporáneos y miembros de una humanidad única (universalidad de la lógica), son tan diferentes de nosotros. Con lo cual, si bien Durkheim no participa en los excesos de Lévy-Bruhl, no deja de participar en los sobreentendidos sobre los que se asientan. Limitada a una modesta antropología del conocimiento primitivo, la sociología, por otro lado, niega su competencia para estudiar la constitución y desarrollo del conocimiento científico. ¿Cómo se fundamenta éste? La solución implícita es que siguiendo los dictados de esa epistemología filosófica que, al principio, se proponía someter a una crítica definitiva.

«¿Cómo pueden, en efecto, comulgar entre sí las conciencias particulares? De dos maneras. O bien fundiéndose las unas en las otras, hasta no constituir más que un espíritu colectivo, o bien comulgando en un mismo objeto que es el mismo para todos, guardando sin $\mathrm{cm}$ bargo cada una su personalidad, como las mónadas de Leibniz, que cada una expresa el universo en su conjunto sin dejar de expresar su individualidad. El primer procedimiento es el del pensamiento mitológico; el segundo, el del pensamiento científico» (Durkheim, 1955: 137). La disolución de la conciencia común o de la solidaridad mecánica es, así, la precondición social para que surja la ciencia moderna.

${ }_{25}$ A este respecto, en Les Formes... se especifica lo siguiente: «Aun cuando estén elaborados siguiendo todas las reglas de la ciencia, los conceptos no logran únicamente su autoridad a causa de su valor objetivo. Para que se crea en ellos no basta con que sean verdaderos. Si no concuerdan con las otras creencias, con las otras opiniones, en una palabra, con el conjunto de las representaciones colectivas, serán negados; las conciencias se cerrarán a ellos; será, por consiguiente, como si no existieran. Si en la actualidad basta con que Ileven la impronta de la ciencia para obtener algo así como un crédito privilegiado es porque tenemos fe en la ciencia. Pero esta fe no difiere esencialmente de la fe religiosa (...) $\mathrm{L}$ a ciencia sigue dependiendo de la opinión» (Durkheim, 1912: 625-626). 
Este fracaso final no debería, con todo, llevarnos a menospreciar la intentona durkheimiana. Se trata, en realidad, de un fracaso interesante - por aleccionador - y que tiene algo de grandioso. En efecto, Durkheim tuvo la valentía de rebelarse avant la lettre contra la reductora delimitación de la sociología del conocimiento que la condenaba a ser una disciplina auxiliar de la epistemología ${ }^{26}$ y contra el dogma que establecía que sólo los filósofos eran competentes para resolver el problema del conocimiento. El problema con su rebelión es que no fue lo suficientemente lúcida y radical. Se lo impedían dos creencias fuertemente arraigadas: la creencia en que el conocimiento tenía un problema insoslayable de fundamentación y la creencia en que la ciencia, en sí misma, era sociológicamente inabordable. Si hubiera sidó más radical, su crítica podría haber conmovido los cimientos de estas dos creencias, desvelando, por un lado, que los fracasos de los filósofos ante el «hueso» de la epistemología eran lógicos e irredimibles por tratarse de un falso problema - y por eso irresoluble - y, por otro lado, que también la ciencia era una práctica social sobre la que la sociología, aunque no lo pueda decir «todo», puede decir mucho. En tal caso, la sociología del conocimiento habría podido disponer, desde el principio, de un instrumental analítico adecuado para acometer, con garantías de éxito, el reto planteado por la moderna teoría postempírica de la ciencia y encarar ese conjunto de «anomalías» — para la epistemología clásica - que resultan de las investigaciones de Quine, Kuhn, Hess, Feyerabend y Rorty, por citar los casos más destacados. Para responder a este reto y leer esas «anomalías» carece de interés una variante sociológica de la epistemología, tal como la propuso Durkheim; más útil y fructífera podría haber sido una sociología del conocimiento radical y segura de sí misma, libre de toda obsesión por el fantasma de la epistemología.

3. Pero volvamos al punto de arranque, al tiempo. En el marco de esta teoría de las categorías, el tiempo es concebido como una representación colectiva cuyos fundamentos ha de proporcionar la sociología. Esa fundamentación propone una reducción social del tiempo o, dicho en otros términos, que toda proposición temporal es traducible a, y derivable de, una proposición sobre la estructura social.

Para conseguir esta reducción sigue Durkheim un doble itinerario: un primero más genérico, pero etnográficamente más ilustrado, en el que se subraya el carácter social de las categorizaciones temporales o calendarios ${ }^{27}$;

${ }^{26}$ Véase, en este sentido, la crítica durkheimiana a la Soziologie des Erkennens de W. Jerusalem (Durkheim, 1910: 42-45).

27 La definición durkheimiana del tiempo se aproxima, en un principio, a la newtoniana («es un marco abstracto $\mathrm{c}$ impersonal que envuelve nuestra existencia individual y social») (Durkheim, 1912: 14), para concretarse a continuación en términos operacionales («es un cuadro ilimitado en el que se despliega bajo los ojos del espíritu toda duración y donde pueden ser situados todos los acontecimientos posibles en relación a puntos de referencia fijos y determinados») (Durkheim, ibid.: 14), es decir, privilegiando a los instrumentos que nos sirven para ordenarlo y medirlo, los calendarios. Acto seguido, aparece la reducción 
un segundo, más especulativo, en el que se deriva la estructuración del tiempo del intrínseco dualismo de la vida social. En cuaquiera de los casos, la reducción fracasa.

En el primero de los itinerarios, Durkheim comete al menos dos errores. El primero reproduce lo que ya se ha visto como característica sobresaliente de su sociología de las categorías, esa confusión de categoría y categorización o, en este caso, de tiempo y temporalización. En efecto, mostrar, como Durkheim se afana en hacer, que las temporalizaciones primitivas o calendarios son representaciones colectivas no es tanto como demostrar que el tiempo, en sí mismo, lo sea. El segundo error radica en que toda su argumentación es una tautología que en poco resuelve el problema de la reducción social del tiempo. En efecto, lo que Durkheim sostiene es que los calendarios son representaciones colectivas porque no hacen sino reflejar el tiempo social; ahora bien, como, en buena lógica durkheimiana, el tiempo social no puede ser sino una representación colectiva, el argumento resulta simplemente circular.

Con el segundo itinerario, el más especulativo, Durkheim pretende mostrar cómo se origina esa estructuración del tiempo que se refleja en los calendarios. Prolongando un argumento de Hamelin sobre el espacio (Durkheim, 1912: 15), sostiene que los marcos temporales sólo cumplen su función de orientación si están interiormente estructurados, es decir, si reciben una diferenciación interior que permita pasar de la idea de un continuo homogéneo a la de un orden discreto heterogéneo. Esa estructuración se produciría en los medios sociales efervescentes y sería el resultado del dualismo característico de la vida social. En esas situaciones se diferenciarían al menos dos tiempo cualitativamente diferentes, «tiempos sagrados y tiempos profanos» (Durkheim, 1912: 499). Dada esta diferenciación - cuyo origen y expresión ubica Durkheim en la fiesta (Durkheim, 1912: 499-500)- emergería un tiempo orientado y público, ese tiempo que denomina «total..., impersonal y global» (Durkheim, 1912: 631), en el que se subsumen y coordinan los múltiples tiempos cósmicos, cotidianos e individuales.

Una propuesta así tiene el doble inconveniente de no brindar una seria solución al problema que quiere abordar y de generar dificultades de largo alcance. No brinda una solución porque lógicamente postula una previa dualización del tiempo. ¿Qué es, cómo se explica ese otro tiempo continuo y homogéneo que, como el newtoniano, fluye sin referencia a nada y que acaba siendo estructurado sagradamente? Durkheim se limita a presentarlo como un dato previo no susceptible de análisis sociológico. Si esto es así, entonces carece de justificación

social del tiempo-calendario: a) «la categoría de tiempo expresa un tiempo común al grupo, el tiempo social» (ibid.: 15); b) «la observación establece que estos puntos de referencia indispensables por los cuales son clasificadas en el tiempo todas las cosas son tomados de la vida social» (ibid.: 14-15). 
la pretendida reducción social del tiempo que, afectando al tiempo sagrado, no alcanzaría a ese otro tiempo (¿newtoniano?) previo e inexplicable.

Pero la apuesta por el dualismo tiene repercusiones aún más graves y de mayor alcance, pues bloquean, o al menos dificultan seriamente, el desrrollo de una sociología sistemática del tiempo. En efecto, sostener que las categorías temporales sólo surgen en condiciones extracotidianas (medios sociales efervescentes) es tanto como negar que puedan hacerlo en condiciones sociales cotidianas o, más estrictamente, en los medios sociales extraños a la reproducción ritual ${ }^{28}$. Consecuentemente - y habrá ocasión de comprobarlo en el artículo que seguirá a éste-, la socioantropología del tiempo se autolimita al estudio de los calendarios sagrados y las interacciones rituales, dejando de lado, a no ser para considerarlos como puros derivados, los calendarios profanos y las interacciones no-rituales ${ }^{29}$.

El resultado final es que Durkheim no consigue argumentar convincentemente que el tiempo se pueda reducir socialmente. Este fracaso no puede sorprender porque, más allá del ingenio y fortuna de las específicas argumentaciones durkheimianas, es el destino ineludible de toda empresa imposible. La de Durkheim lo era por razones generales: no ya por pretender una reducción social, sino por pretender una reducción. Es esto lo que resulta manifiestamente imposible.

Sin ser consciente de ello, el mismo Durkheim lo había mostrado en su crítica a las teorías empíricas y racionalistas de las categorías y, consecuentemente, del tiempo. Contra las primeras había aducido una variante de la objeción kantiana de que no es lo mismo una sucesión de percepciones que la percepción de la sucesión; contra las segundas había mostrado que postular el tiempo como un a priori no suponía explicarlo. En cualquiera de los casos, lo que Durkheim había desvelado era la imposibilidad de reducir el tiempo a alguna otra cosa, aunque él creyera haber demostrado la insuficiencia de ciertas reducciones, no de la reducción en sí.

La razón de que la reducción sea imposible radica en que está condenada a entrar en contradicción consigo misma, es decir, a romper las reglas del juego que propone y que obligan a que aquello a lo que algo se reduce - y de lo que se deriva-- sea más básico y simple que lo reducido. Ahora bien, el tiempo constituye un dato inmediato, simple y básico de la experiencia interior y exterior que resulta manifiestamente imposible reducir a, o derivar de, algo que sea más inmediato, básico y simple. Toda reducción que intente sortear esta barrera lógica o resulta un fracaso, pues recurre a simples trucos verbales, o todo lo más se limita a crear una apariencia de reducción

${ }^{28}$ Véase $H$. Joas (1984: 570-572), que critica, desde una perspectiva pragmatista, esa disociación de lo cotidiano y extracotidiano en la teoría durkheimiana del tiempo.

3 Se trata de una servidumbre del dualismo durkheimiano que, por lo demás, explica el relativo éxito de su aproximación al tiempo en el campo de la antropología y su limitada incidencia en el de la sociología. 
que acaba mostrándose como circular o tautológica: lo que explica al tiempo acaba siendo en tiempo mismo ${ }^{30}$.

4. El fracaso en el que desemboca la teoría durkheimiana del tiempo puede ser aleccionador si se pone atención en distinguir entre lo que intuitivamente se estaba buscando y el resultado final que se alcanzó. ¿Por qué no se conformaba Durkheim con lo que se conformaron sus seguidores posteriores? ¿Por qué no le bastaba una autocontenida y modesta sociología del tiempo y creía imprescindible poner los cimientos de una teoría general del tiempo? Se dirá que por su tendencia hacia las derivaciones filosóficas, por su espíritu generalista y metafísico, y se concluirá condenando sus excesos filosóficos. Al hacerlo, se tirará al niño junto con el agua sucia, porque no se distinguirá lo que es urgente distinguir: las intuiciones de que parte y los resultados a que llega. Las primeras son correctas y es preciso retomarlas y desarrollarlas; son las segundas las que son erróneas por adentrarse en la vía muerta del reduccionismo.

Esas intuiciones sustancialmente correctas se pueden exponer en su forma más general. Por un lado, Durkheim intuyó que cualquier aproximación científica al estudio del tiempo había de apoyarse en una previa teoría del tiempo, pues en caso contrario se desarrollaría a tientas y arbitrariamente. Por otro lado, intuyó también que el problema del tiempo no era ya competencia exclusiva de filósofos metafísicos o epistemólogos, sino que había que tomar en consideración los resultados de las distintas ciencias positivas. Su error consistió en creer que esa teoría había de ser explicativo-reduccionista y que esa explicación la debía aportar su ciencia, la sociología. Pero este error no invalida lo correcto de las intuiciones de que partía. Lo que habrá que hacer es retener éstas y desarrollarlas de forma que no desemboquen de nuevo en un reduccionismo sociológico o en cualquier atro tipo de reduccionismo.

En las páginas siguientes voy a adentrarme en esa dirección: esbozaré las líneas generales de una teoría del tiempo que trascienda los límites que le impuso Durkheim y abordaré el problema general de las relariones entre esa teoría y las distintas ciencias interesadas en el tiempo. La razón de que lo haga radica en que no creo que ninguno de esos cometidos sea un «adorno" filosófico del que una sociología interesada en el tiempo pueda prescindir, sino, muy por el contrario, tareas necesarias y urgentes que si no se acometen bloquean o hacen difícil su desarrollo.

¿En qué ha de consistir básicamente una teoría del tiempo que no apueste por la estrategia explicativo-reduccionista? En una aclaración metódica de su objeto de análisis que nos haga saber de qué hablamos cuando nos referimos al tiempo y de qué maneras distintas podemos hacerlo. Puede parecer demasiado modesto tal objetivo, pero en realidad alcanzarlo es deci-

${ }^{30}$ Para una crítica de las teorías reduccionistas del tiempo y, más específicamente, de las teorías causales, véase Sklar (1977: 318-343). 
sivo, pues gran parte de las disputas sobre el tiempo alcanzarían soluciones satisfactorias si se clarificara previamente sobre qué se disputa o cuáles son los límites de las disputas posibles o sensatas.

Una tal teoría concibe el tiempo como un lenguaje que se usa en múltip'es contextos y propone que su léxico, gramática y sintaxis se pueden fijar, sistematizar y aclarar, tanto global como regionalmente. Se supone así que el tiempo no es necesariamente un objeto inefable y laberíntico, imposible de ordenar y carente de mapa o, dicho de otra manera, que las perplejidades agustinianas son tan sólo un punto de arranque retórico, no un resultado infranqueable ${ }^{31}$. La aciaración ha de ser global y regional porque el tiempo se dice de muchas maneras: cada una de ellas es un lenguaje regional del tiempo; su conjunción, el lenguaje global. Lógicamente, aclarar este último es la llave para aclarar el primero. Para hacerlo, la mejor estrategia es aquella que intenta fijar los límites del lenguaje temporal y su estructura mínima. Por límites se entiende aquella frontera ideal que permite separar lo propiamente temporal de aquello que no lo es: fijan dónde acaban las disputas sobre el tiempo y dónde empieza otro orden de problemas y disputas. La estructura, por su lado, establece el orden mínimo e irreductible de elementos cuyas determinaciones y relaciones pueden variar según reglas precisas. Fijada la estructura del tiempo, se comprende, pues, la lógica y los límites de variación de los múltiples tiempos de que hablan, por ejemplo, físicos, biólogos, psicólogos, antropólogos y sociólogos.

La delimitación del tiempo no puede ser sino variable según contextos y relativamente difusa. En efecto, el problema fundamental de delimitación no es otro que el de fijar las fronteras entre el tiempo y los procesos. Es un viejo problema sobre el que se han acumulado advertencias y soluciones por lo menos desde los tiempos de Aristóteles ${ }^{32}$. Pero se trata también de un problema persistente y que estará siempre abierto. La causa es que una distinción radical y universalizable es imposible al menos por dos razones: el lenguaje temporal -incluso el más abstracto, como el de los Principia- se

31 Prueba de ello es el discurso sobre el tiempo que se construye en el Libro XI de Las Confesiones (Agustín de Hipona, 1984: 315-347): ese inicial saber que no se sabe decir («si nadie me lo pregunta lo sé; pero si quiero explicárselo al que me lo pregunta, no lo sé») resulta ser un saber decible que, al final, propone que el tiempo es una distentio animi. Como ha destacado Wittgestein, San Agustín propone en realidad que para saber qué es el tiempo tenemos que recordar y clarificar sus múltiples usos, solucionar sus rompecabezas, clarificar sus malentendidos. «Lo que se sabe cuando nadie nos pregunta, pero va no se sabe cuando debemos explicarlo, es algo de lo que debemos acordarnos (...) Nos acordamos (...) del tipo de enunciado que hacemos sobre los fenómenos. De ahí que San Agustín se acuerde también de los diversos enunciados que se hacen sobre la duración de los sucesos, sobre su pasado, presente o futuro» (Wittgestein, 1988: 113).

${ }^{32}$ Aristóteles enuncia y afronta el problema en el Libro IV de La Física, proponiendo, en contra de Platón, que «el tiempo no es el movimiento ni existe sin el movimiento», reconduciendo el problema al de determinar «qué elemento del movimiento es el tiempo» (Aristóteles, Física: Libro IV, cap. 11). Van Fraassen (1985: 11-30) analiza el legado aristotélico hasta la introducción del concepto de tiempo absoluto de Newton. 
edifica sobre metáforas (el río, la vida, las edades, etc.) que no hacen sino absolutizar tipos determinados de procesos ${ }^{33}$; por otro lado, el grado de abstracción de los distintos lenguajes temporales es muy variable, tanto desde un punto de vista contemporáneo (distintos contextos de habla simultáneos) como de uno histórico-evolutivo (distintas culturas humanas), lo que hace que en unos casos aparezca indiferenciado lo que en otros está diferenciado ${ }^{34}$.

Todas estas razones llevan a que las delimitaciones sean variables y relativamente difusas, pero no niegan que haya un principio de delimitación y que éste deba ser tenido en cuenta. Es evidente que los procesos hacen referencia a estados/acontecimientos del mundo y que el tiempo se limita a ciertos aspectos - abstraíbles y generalizables - que aparecen en ellos. Significa esto que el tiempo es un concepto más abstracto que el de proceso y que, consecuentemente, si bien debemos utilizar nuestro lenguaje temporal para describir los procesos, no podemos proyectar indiscriminadamente el lenguaje procesual sobre el tiempo. Un ejemplo bastará para aclarar esta asimetría entre el tiempo y los procesos. Una característica crucial de los procesos es su reversibilidad o irreversibilidad; se trata de una característica determinable teóricamente - pues no se puede identificar reversión fáctica y reversibilidad- que ciertamente hace referencia al tiempo, pues lo reversible es aquello que se puede volver a dar idéntico a sí mismo o, más estrictamente, una secuencia de estados invertible. Pero sería un error inferior de esto que el tiempo es reversible o irreversible; la reversibilidad no es una determinación que se pueda predicar del tiempo, a pesar de que se pueda predicar de los procesos ${ }^{35}$.

Diferenciar tiempo y proceso es, por lo demás, del máximo interés en las ciencias sociales. A falta de esa diferenciación se puede llegar a una errónea delimitación del campo de problemas de la sociotemporalidad. Dos ejemplos bastarán para mostrarlo. Si se leen los trabajos de Sorokin (1964: 171-173) y Gurvitch (1969, II: 341-344) sobre el tiempo social, resulta muy claro que el primero lo define sin distinguirlo de los procesos y que el segundo construye una tipología de temporalidades que no son sino un calco - con terminología exótica- de distintos procesos sociales. Si, yendo más allá de la sociología, se leen los estudios de Braudel (1980: 60-106) sobre las características de la nueva historia no episódica, aparece un error similar: se identifican como tiempos de la historia distintos tipos de procesos.

${ }^{33}$ Una interesante aproximación a las metáforas primordiales bajo las que se concibe el tiempo se encuentra en Brumbaugh (1984: cap. 9).

${ }^{34}$ Por tomar el ejemplo que proporciona Evans-Pritchard (1977: 111-127), el hecho de que los Nuer no dispongan de un concepto de tiempo tan abstracto como el nuestro y tiendan a identificarlo con lo que nosotros llamamos procesos, no da pie para inferir que carezcan de específicos conceptos temporales o que vivan en una confusión absoluta entre tiempo y proceso. Hacerlo sería optar por un radical etnocentrismo.

${ }^{35}$ Sobre las relaciones entre tiempo y reversibilidad hay un cuidadoso análisis conceptual en Bunge (1972: 122-130). 
Delimitado el tiempo, una teoría aclaratoria del tiempo debería proceder a fijar su estructura. Sin entrar en el problema de si el tiempo es un existente (Newton) o una relación entre existentes (Leibniz), si está en lo que se conoce (Aristóteles) o en el sujeto conocedor (Kant), es decir, sin entrar en los problemas ontoepistemológicos que durante siglos han debatido los filósofos, sabemos que al tiempo o a lo temporal le asignamos o reconocemos específicas propiedades. Tales propiedades constituyen la estructura del tiempo tal como la define un determinado discurso (la física o la sociología, por ej.). Como esa estructura difiere, como el tiempo se puede decir y se dice de muchas maneras, habrá que fijar cuál es la estructura global, es decir, cuáles son las propiedades que se pueden determinar y combinar de forma cambiante según contextos.

Creo que se adelanta mucho en este campo si se propone que esa estructura es irreductiblemente dual, es decir, que por mucho que se intente reducir la complejidad inmediata del tiempo siempre acabaremos utilizando al menos dos lenguajes temporales, irreductibles entre sí, que en la historia han encontrado una primera y unilateral expresión en Aristóteles y San Agustín. El primer tipo, el que informa la definición aristotélica del tiempo como número del movimiento según el antes y el después, lo presenta como un conjunto interiormente diferenciado de propiedades relacionales de tipo ordinal, topológico y métrico. El segundo tipo, el que se expresa en la definición agustiniana del tiempo como una distensión (extensión/desgarro) del alma ${ }^{36}$, lo presenta como un conjunto de propiedades cualitativas que definen distintos horizontes práctico-cognitivos. En el primer caso, el tiempo nos dice si lo que acontece es anterior, posterior o simultáneo a algún otro acontecimiento, cuántos puntos de referencia precisamos para localizarlo, cuánto dura; en el segundo, el tiempo se nos presenta como el devenir, es decir, como la precipitación de lo futuro en lo que es presente y la fijación de éste en lo que es pasado. Pero veámoslo más detenidamente.

En cuanto que conjunto de propiedades relacionales, el tiempo aparece diferenciado al menos en tres subestructuras ${ }^{37}$. Cada una de ellas es relativamente autónoma. Esas subestructuras son, como se anunció antes, ordinales, topológicas y métricas.

Como parte de un conjunto ordinal, las relaciones temporales aparecen como sucesión (antes/después) o simultaneidad (a la vez que), formando un orden (total o parcial) binario. En algunos casos, fundamentalmente cuando aparecen topologías «atípicas», esas relaciones se ordenarán según tríadas (intermediación: $b$ se sitúa entre $a$ y $c$ ) o tétradas (par-separación: $a$ y $c$ parseparan $b \quad \mathrm{y} d)^{38}$. Como complejo topológico, el tiempo es un conjunto de

${ }_{36}$ Un buen estudio sobre el concepto agustiniano de la distentio animi aparece en Ricouer (1983, I: 19.53).

${ }^{37}$ Sigo las propuestas de Kroes (1985: 4-5) sobre la estructura del tiempo de la física.

${ }^{38}$ Véase Van Fraassen (1985: 66-70). 
relaciones básicas que hacen referencia a la continuidad, conectividad, dimensionalidad, orientabilidad, apertura, etc. En este caso, al definir la topología de un determinado tiempo podemos establecer, por ejemplo, si es continuo o discreto, si es unidimensional, bidimensional o n-dimensional, si es abierto (como la recta) o cerrado (como el círculo), si tiene principio y final o principio sin final o carece de ambos, si es orientable y está orientado o es orientable y no está orientado, etc. No existe razón lógica o empírica para suponer que la topología del tiempo tenga que poseer las propiedades de la recta matemática, como pretendían Newton y Kant. Está claro que el desarrollo de la física ${ }^{39}$ y, más allá de ésta, la evidencia etnográfica e historiográfica permiten definir múltiples topologías del tiempo, cada una con propiedades específicas.

Por último, en cuanto que complejo métrico, el tiempo nos permite medir intervalos entre acontecimientos, es decir, dar cuenta del aspecto duracional de la experiencia. Entendido en un sentido amplio --que toma en consideración la diversidad de calendarios y «relojes» que han utilizado las distintas culturas humanas-, el tiempo como conjunto susceptible de medida nos sirve para determinar el cuánto y el cuándo, es decir, asignar cantidades a la duración y ubicación al acontecer. Según prime lo segundo sobre lo primero - lo que es propio de los calendarios sagrados-, el complejo cuasi-métrico se convierte en un complejo clasificatorio que asigna cualidades distintas a cada unidad discreta de tiempo. Es obvio, por lo demás, que no sólo los instrumentos o puntos de referencia de medición son muy variables a lo largo de la historia humana, sino que también puede diferir la métrica que se supone intrínseca al tiempo, como muestra el desarrollo de la moderna física.

Está claro que lo anterior no agota nuestro lenguaje temporal: el tiempo no se limita a ordenar el acontecer o asignar una cantidad a la duración, sino que se supone también —utilizando una metáfora omnipresente- que «pasa». Este pasar del tiempo hace referencia al devenir, a la otra cara de lo temporal. El devenir es definible como la estructuración o integración del pasado, presente y futuro. Esa integración se puede concebir, al menos, de dos maneras ${ }^{40}$ : como una integración de modalidades, o al modo de la fenomenología agustiniana, que concibe pasado y futuro como horizontes del presente, definiendo cada uno de ellos específicas perspectivas práctico-cognitivas: el pasado es lo que podemos recordar y sobre lo que no podemos actuar, mientras que el futuro es lo que podemos esperar e intentamos determinar, y el presente la encrucijada a la que atendemos, desde la que recordamos y para la que esperamos.

Es evidente, por otro lado, que el devenir se puede concebir de muchas maneras y que así aparece en las distintas culturas humanas. En efecto, la

${ }^{39}$ Sobre las múltiples topologías del tiempo que se toman en consideración en la física actual, véase Sklar (1977: 296-317).

${ }^{40}$ Véase Luhmann (1982: caps. 12 y 13), que ha explorado ambas vías. 
idea de un futuro abierto y su corolario típico, la contraposición de la experiencia y la expectativa, es relativamente moderna, dependiendo de ciertas condiciones que son objeto de estudio de historiadores y sociólogos ${ }^{41}$. Es posible concebir el futuro como lo cerrado o incluso, como se tiende en la actualidad, como una catástrofe que induce a que el devenir se colapse totalmente en el presente ${ }^{42}$. Estas rápidas precisiones sirven para destacar que, lo mismo que el tiempo como conjunto relacional puede determinarse de muchas maneras, ese otro tiempo cualitativo del devenir también se puede configurar de forma cambiante.

Aclarar la estructura del tiempo no constituye, pues, un baldío ejercicio de especulación del que la sociología interesada por lo temporal pueda prescindir. La estructura del tiempo fija sus propiedades -aquellas de las que hablamos cuando nos referimos al tiempo-y el orden y límite de sus variaciones. Si se toma en consideración, se puede inferir que los distintos tiempos de que se hab'a en el lenguaje cotidiano y en el de las disciplinas científicas no son sino distintas maneras de establecer las determinaciones ordinales, topológicas, métricas y del devenir de lo temporal, distintas maneras que acceden a una complejidad mayor porque pueden combinarse de forma muy variable entre sí. Puedo, en efecto, suponer un tiempo con una topología cerrada (circular) y combinarlo con una determinada concepción del devenir (mito del eterno retorno). Sólo si tomo en consideración la estructura del tiempo se me ofrecen posibilidades interesantes de aclarar la lógica de una propuesta así.

Quiero abordar ahora la otra cara del problema que se enunció anteriormente: las relaciones entre el tiempo y las distintas disciplinas científicas. Que la ciencia sea relevante para afrontar el problema del tiempo es un viejo tópico, tan viejo como la moderna ciencia postgalileana. Se comprende así por qué toda innovación científica radical ha ido de la mano de una reproblematización del tiempo. La última muestra la proporciona la física postrelativista. El problema, con todo, no radica tanto en seguir mostrando esta relevancia, sino en especificar en qué consiste.

Se ha tendido a pensar esas relaciones o en el marco de una filosofía con preocupaciones epistemológicas o bajo algún esquema reduccionista. Bastarán unas pocas consideraciones para fijar sus características.

${ }^{41}$ La contraposición de la experiencia (del pasado) y las expectativas (cara al futuro) ha sido estudiada por Koselleck como característica de la época moderna y fundamento del concepto contemporíneo de historia (Koselleck, 1985: 267-288). Sobre la dinámica socioevolutiva de la semántica del tiempo se pueden consultar las diversas aproximaciones de Luhmann (1982, 1983).

42 Véase Falk (1988: 388 y ss.), sobre la conversión del futuro (la catástrofe nuclear y/o ecológica) en un hiperacontecimiento, la pérdida consecuente de la relevancia del pasado y su interpretación, y cl colapso del tiempo en un presente que se convierte en espectáculo interminable de acontecimientos que, más que comprenderse o interpretarse, son devorados, curioseados, gustados o detestados. 
El primer enfoque supone que la ciencia -y más especialmente la físicapostula un determinado tipo de tiempo que ella misma no se toma la molestia de analizar y explicar. Es precisa otra disciplina, la epistemología, que aclare qué es ese tiempo, lo depure críticamente y desvele sus fundamentos. Al realizar esta labor, los resultados alcanzados pueden fluctuar entre dos extremos: mostrar, al modo de Kant, cuáles son las características del tiempo (newtoniano), someterlas a una crítica que ponga en cuestión alguna de sus pretensiones (realismo absoluto) y asignarles su verdadero fundamento (su «idealidad trascendental») (Kant, 1985: 78) o mostrar, como hizo Bergson, que tales características y su fundamento pragmático son totalmente extraños al tiempo verdadero (no espacializado) de la intuición inmediata de la durée ${ }^{43}$. En los dos casos se acepta la relevancia del tiempo de los físicos y se está de acuerdo en que son otros, los filósofos, los que deben explicar en qué consiste; la diferencia radica en que Kant hace universal y necesario ese tiempo, mientras Bergson declara su incompatibilidad con otro tenido por primario y verdadero. Lo decisivo, en cualquier caso, es que se suponga la existencia de una instancia superior (el Tribunal Supremo de la Filosofía) que ha de decidir el caso presentado por la física y dictar sus fundamentos de derecho.

El segundo enfoque, el reduccionista, es más radical porque declara que es la ciencia misma la que se basta para «descubrir» qué es el tiempo; no hay instancia suprema ulterior. Aboga, pues, por una estrategia explicativo-reduccionista que propone que el complejo tiempo de la experiencia no es sino la manifestación en la conciencia de ciertas propiedades de algún objeto estudiado por la ciencia. En unos casos pretenderá identificarlo con el de alguna ciencia en particular: la física ${ }^{44}$, pero también, y muy tempranamente, la psicología ${ }^{45}$; en otros casos, de los que en la actualidad es ejemplo relevante Fraser ${ }^{46}$, con el conjunto jerárquico de las disciplinas científicas más relevantes: física (relativista, cuántica, newtoniana), biología, psicología y sociología. En cualquiera de los casos, se supone que el tiempo tiene una estructura determinada y cerrada que describen los enunciados de alguna disciplina científica.

Pero cabe otro tipo de enfoque que, sin negar la relevancia de los resultados de las ciencias, no pretenda agotar el problema del tiempo a partir de alguna disciplina científica o de una ingeniosa combinación de varias. Desde el punto de vista de este enfoque —que me parece el más correcto-, la física,

\footnotetext{
${ }^{43} \mathrm{He}$ analizado la crítica bersoniana al tiempo de la física en el artículo anterior de esta serie.

${ }^{44}$ Un ejemplo son los esfuerzos de Reichembach (1958: 113) por reconducir la complejidad de la experiencia del tiempo a la estructura que le propone la teoría de la relatividad

${ }^{45}$ Un ejemplo es Guyau (1902), un cuasi-contemporánco de Durkheim, que reduce psicológicamente el ticmpo.

${ }^{46}$ Véase Fraser $(1982,1987$ a y $1987 b)$.
} 
biología, psicología o sociología sólo pueden proporcionar teorías regionales del tiempo, mostrar distintos usos del lenguaje temporal que ninguna de ellas puede agotar ni pretende universalizar. De este modo, por ejemplo, se puede estudiar el tiempo de la física sin pretender aislar la esencia universal de toda experiencia temporal. Lo que entonces se haría es ver de qué manera la física o los físicos determinan la estructura del tiempo: cuál o cuáles son las métricas que al tiempo se le suponen, cuál o cuáles sus topologías, cuál o cuáles las relaciones ordinales y dentro de qué límites (por ej.: si la simultaneidad o la sucesión son relativas o absolutas), cuál es la idea de devenir y cómo se sitúan en ella los distintos tipos de procesos (problema de la reversibilidad). Se fija así, doblemente, el lenguaje temporal de la física y la estructura temporal que se le supone a la materia. Fijado esto, se podrían comparar las distintas estructuras temporales que coexisten o se suceden en la historia del discurso físico.

Este ejemplo se puede proyectar sobre las otras disciplinas científicas. El caso de la sociología es uno más. También se puede reconstruir el tiempo de la sociología o de las ciencias sociales. Pero de la relevancia de esta información no se puede derivar, al modo durkheimiano, hacia una teoría sociológica del tiempo con pretensiones de universalidad y suficiencia. Todo lo más podemos centrar nuestros esfuerzos en clarificar de qué manera los sociólogos (o los historiadores) temporalizan su objeto de estudio y cuáles son las características de las estructuras temporales que informan las interacciones sociales. En este último caso se entraría ya en lo que se ha dado en llamar la sociología del tiempo, es decir, en esa rama de estudios que esbozaron Durkheim y los durkheimianos y que se abordará en el siguiente artículo.

\section{BIBLIOGRAFIA}

Agustín de Hipona (1984): Confesiones, Barcelona, Bruguera.

Aristóteles (1977): Física, en Obras, Madrid, Aguilar.

Broor, D. (1982 a): «Durkheim and Mauss revisited: classifications and the sociology of knowledge», Studies in History and Pbilosopby of Science, 13: 267-297.

- (1982 b): «Reply to Steven Lukcs», Studies in History and Pbilosophy of Science, 13: 319.323.

Braudel, F. (1980): La bistoria y las ciencias sociales, Madrid, Alianza.

Brumbaugh, R. (1984): Unreality and time, Albany, State University of New York Press. BUNGe, M. (1972): «Time assymetry, time reversal and irreversibility», en Fraser (ed.), The study of time, I, Nueva York, Springer-Verlag: 122-130. 
Durkheim, E. (1910): «Reseña de W. Jerusalem, "Soziologie des Erkennens", Die Zukunft 1909», Année Sociologique, XI: $42-45$ (reproducido en Textes, París, Minuit: I: 190-194).

- (1912): Les formes ćlémentaires de la vie réligieuse, París, Alacan (citas por ed. PUF, París, 1968).

- (1913): «Rescña de Lévy-Bruhl, Les fonctions mentales dans les sociétés inférieures», Année Sociologique, XII: $33-37$ (reproducido en Journal Sociologique, 1969, París, PUF: 677-681).

- (1955): Pragmatisme et Sociologie, París, Vrin (citas por traducción: Pragmatismo y Sociología, Bucnos Aires, Schapire).

Durkheim, E., y Mauss, M. (1903): «De quelques formes primitives de classification: contribution à l'étude des représentations collectives», Année Sociologique, VI: 1-72 (reproducido en Journal Sociologique, 1969, París, PUF: 395-461).

Evans-Pritchard, E. (1977): Los Nuer, Barcelona, Anagrama.

FALK, P. (1988): «The past to come», Economy and Society, 17, 3: $374-394$.

Fraser, J. T. (1982): The genesis and evolution of time, Brighton, Harvester.

- $(1987$ a): Time, the familiar stranger, Amherst, Univ. of Massachussets Press.

- $(1987$ b): «Saliendo de la caverna de Platón: la historia natural del tiempo», Revista de Occidente, 76: 5-34.

Gurvitch, G. (1969): «La multiplicité des temps sociaux», en La vocation actuelle de la sociologic, Paris, PUF: II: 325-430.

Guyau, M. (1902): La génèse de l'idée de temps, París, Alcan.

Hesse, M. (1982): «Comments on the papers of David Bloor and Steven Lukes», Studies in History and Pbilosoplby of Science, 13: 325-331.

Horton, R. (1980): Lévy-Brubl, Durkbeim y la revolución cientifica, Barcelona, Anagrama.

JOAS, H. (1984): «Durkheim et le pragmatisme. La psicologie de la conscience et la cons. titutions sociales des catégories», Revtue Française de Sociologie, XXV: 560-581.

Kant, I. (1985): Crítica de la razón pura, Madrid, Alfaguara.

Koselteck, R. (1985): Fatures Past. On the semantics of bistorical time, Cambridge (Mass.), MIT Press.

KroEs, P. (1985): Time: its structure and role in physical theories, Dordrecht (Hol.), Reidel.

LÉvi-Strauss, C. (1971): El totemismo en la actualidad, México, FCE.

- (1972): El pensamiento salvaje, México, FCE.

Lummann, N. (1982): The differentiation of society, Nueva York, Columbia University Press.

- (1983): Struttura della società e semantica, Roma-Bari, Laterza.

Lukes, S. (1973 a): Enile Durkbein, Londres, Penguin.

- (1973 b): "On the social determination of truth», en R. Horton y R. Finegan (eds.) Modes of Thought, Londres, Faber \& Faber: 230-248.

- (1982): «Comment on David Bloor», Studies in History and Pbilosopby of Science, 13: $313-318$.

Namer, G. (1977): «La sociologie de la connaissance chez Durkheim et chez les durkheimiens», Année Sociologique, 28: 41-77.

Reichenbach, H. (1958): The philosophy of time and space, Nueva York, Dover.

Ricoeur, P. (1983): Temps et recit (tomo I), París, Seuil.

Ronty, R. (1983): La filosofía y el espejo de la naturaleza, Madrid, Cátedra.

Skinr, L. (1977): Space, time and spacetime, Berkeley, Univ. of California Press.

Sorokin, P. (1964): Sociocultural causality, space, time. A study of referential principles in sociology, Nueva York, Russell \& Russell. 
Sorokin, P., y Merton, R. (1937): «Social time: a methodological and functional analysis», American Journal of Sociology, 42, 5: 615-619; recogido en S. TABBoni (ed.), T'mpo c società (1985), Milán, Angeli: $35-46$ (citas por ed. de Tabboni).

Van Frassen, B. (1985): An introduction to the pbilosopby of time and space, Nueva York, Columbia Univ. Press.

Wittgestein, L. (1988): Invesilgaciones filosóficas, Barcelona, Crítica. 